\title{
A PESQUISA COMO PRINCÍPIO PEDAGÓGICO E SUA MATERIALIDADE LINGUÍSTICA: ESTUDANTES DA EDUCAÇÃO PROFISSIONAL TÉCNICA DE NÍVEL MÉDIO
}

\author{
Salete Valer \\ Instituto de Educação, Ciência e Tecnologia de Santa Catarina \\ DOI: 10.15628/rbept.2019.7289
}

Artigo submetido em maio/2018 e aceito em abr/2019

\begin{abstract}
RESUMO
As políticas educativas nacionais apontam a pesquisa como princípio pedagógico e a tecnologia de informação e comunicação como conteúdos essenciais para a formação geral e profissional. Esta pesquisa em Psicolinguística Aplicada objetiva testar estratégias para a ampliação da competência produtiva escrita dissertativa por meio da unidade de ensino ensaio curto dissertativo na Educação Profissional Técnica de Nível Médio. A metodologia foca na pesquisa-ação, o teste como instrumento e estudantes do Curso Técnico Subsequente em Panificação e Confeitaria como sujeitos da pesquisa. Os resultados indicam que todos os estudantes que participaram das atividades propostas na intervenção qualificaram em grande escala a textualização das variáveis em análise, porém os estudantes com déficit no uso das TIC tiveram dificuldades em desenvolver todo o conteúdo selecionado. Conclui-se que a habilidade com essas tecnologias se torna indispensável para a prática efetiva do letramento conforme está sendo proposto nas diretrizes para a qualidade da educação.
\end{abstract}

Palavras-Chave: Educação professional. Curso Técnico Subsequente. Ensaio curto dissertativo.

\section{RESEARCH AS A PEDAGOGICAL PRINCIPLE AND ITS LANGUAGE MATERIALITY: STUDENTS FROM A TECHNICAL PROFESSIONAL EDUCATION PROGRAM}

\begin{abstract}
National educational policies perceive research as a pedagogical principle and information and communication technology as essential content for general and professional education. This research in the area of Applied Psycholinguistics aims at testing strategies for the development of dissertative written production competence of the students attending the Technical Professional Education Program during the teaching unit of dissertative short essay. The methodology focuses on action research, the test as an instrument, and the students of the Subsequent Technical Course in Bakery and Pastry as subjects of the research. The results indicate that all the students who participated in the activities proposed in the intervention qualified, in a large scale, the textualization of the variables under analysis, but the students with a deficit in the use of Information and Communication Technology (ICT) had difficulties in developing all the selected content. The study suggests that having skills in such technologies is indispensable for the effective practice of literacy the way it is proposed in the guidelines for a qualified education.
\end{abstract}

Keywords: Professional education. Technical Course. Dissertative short essay. 


\section{TÍTULO DAS SEÇÕES}

A Resolução ํo 6, de 20 de setembro de 2012 (BRASIL, 2012a), lançada pelo Ministério da Educação indica que a Educação Profissional Técnica de Nível Médio está inserida na Educação Básica, sendo uma modalidade de educação complementar ao Ensino Médio, a qual pode ser ofertada de forma integrada, concomitante ou subsequente. Essa resolução dá as bases para a elaboração do Catálogo Nacional para os Cursos Técnicos (CNCT) (BRASIL, 2012b, p.149), cujo documento esclarece que essa modalidade educativa é

um curso de nível médio que objetiva capacitar o aluno com conhecimentos teóricos e práticos nas diversas atividades do setor produtivo. Acesso imediato ao mercado de trabalho é um dos propósitos dos que buscam esse curso, além da perspectiva de requalificação ou mesmo reinserção no setor produtivo. [Grifo nosso].

Do conteúdo que está apresentado no respectivo catálogo, observase que é objetivo dessa modalidade de educação desenvolver no estudante primeiramente a capacidade de lidar com os aspectos que envolvem a teoria do objeto de ensino. Isso significa dizer que o estudante deve ser capaz de ler e escrever sobre o quadro teórico-metodológico do objeto em estudo. Esse saber fornece as condições necessárias à ampliação da capacidade para a prática do objeto de aprendizagem, promovendo, desse modo, no estudante uma prática criativa e não meramente executora.

Em outras palavras, quando se fala em Educação Profissional Técnica de Nível Médio, em quaisquer das suas formas de oferta, a formação geral do aluno deve se tornar inseparável da formação profissional e viceversa. Para isso deve-se enfocar o trabalho como princípio educativo, a fim de superar "a dicotomia historicamente cristalizada da divisão social do trabalho entre a ação de executar e as ações de pensar, planejar, dirigir, supervisionar ou controlar a qualidade dos produtos ou serviços." (BRASIL, 2013, p. 207). Com isso, incorpora-se a dimensão intelectual ao trabalho 
produtivo, buscando, destarte, a formação de trabalhadores capazes de atuar democraticamente como cidadãos, na posição de dirigentes ou de subordinados.

Essa dicotomia entre ensino técnico para as classes desfavorecidas socioeconomicamente e educação propedêutica para as classes abastadas, historicamente existente, deve ser rompida nas diferentes instâncias educativas pela adoção da pesquisa como princípio pedagógico. (BRASIL, 2013, p. 19). Esse princípio pedagógico é o meio pelo qual a instituição de ensino oferece as condições necessárias e adequadas para que o estudante, em qualquer modalidade e nível da Educação Básica atinja o acessopermanência-sucesso-progressão no decorrer do seu processo educativo. Isso significa dizer que a pesquisa como prática social, objeto de ensino e aprendizagem no processo de escolarização tem por fim desenvolver nos estudantes habilidades cognitivas para interpretar teorias, relacionar, analisar, criticar, refletir, rejeitar ideias fechadas, aprender, buscar soluções, propor alternativas etc. Esses conhecimentos constituídos pela linguagem se materializam por textos específicos em decorrência da sua função social. Esses saberes contribuem para que o sujeito tenha sucesso no processo de aprendizagem e tenha as condições necessárias para progredir também nos estudos e não somente no trabalho. Assim, observa-se a relevância do aprendizado dessa prática social da linguagem processo de escolarização.

O Instituto Federal de Educação, Ciência e Tecnologia de Santa Catarina, Campus Florianópolis, local em que esta pesquisa ocorre, oferece, no momento, os cursos técnicos de Guia de turismo, Gastronomia, Eventos, Panificação e Confeitaria. De acordo com CNCT (BRASIL, 2012b), o eixo tecnológico Turismo, Hospitalidade e Lazer compreende

[...] tecnologias relacionadas aos processos de recepção, viagens, eventos, serviços de alimentação, bebidas, entretenimento e interação. Abrange os processos tecnológicos de planejamento, organização, operação e avaliação de produtos e serviços inerentes ao turismo, 
hospitalidade e lazer. As atividades compreendidas neste eixo referem-se ao lazer, relações sociais, turismo, eventos e gastronomia, integradas ao contexto das relações humanas em diferentes espaços geográficos e dimensões socioculturais, econômicas e ambientais. A pesquisa, disseminação e consolidação da cultura, ética, relações interpessoais, domínio de línguas estrangeiras, prospecção mercadológica, marketing e coordenação de equipes são elementos comuns deste eixo. São traços marcantes da organização curricular destes cursos: ética, educação ambiental, normas técnicas e de segurança, historicidade, empreendedorismo, redação técnica, além da capacidade de trabalhar em equipes, com iniciativa, criatividade e sociabilidade. (BRASIL, 2012b, p.146, grifo nosso).

Isso significa dizer que todo estudante da Educação Profissional Técnica de Nível Médio deve desenvolver quatro atividades cognitivas fundamentais: planejar, organizar, operar e avaliar produtos e serviços.

Sabe-se que toda atividade cognitiva se constitui pela linguagem, mais especificamente, por meio de textos orais e escritos específicos a cada situação sociodiscursiva. Em relação às habilidades cognitivas relativas ao planejamento e à avaliação de produtos e serviços, essas habilidades se concretizam linguisticamente por meio dos textos projeto e relatório respectivamente. A atividade cognitiva organização se concretiza por textos específicos ao contexto sociodiscursivo em que a operação/prática deve se efetivar. Toma-se como exemplo o Curso Técnico em Gastronomia em que os gêneros textuais receita e ficha técnica são resultantes de uma sequência de conceitos teóricos como, por exemplo, práticas de higiene e manipulação de alimentos, técnicas de corte, preparação de molhos e fundos, técnicas de cocção, aspectos nutricionais dos insumos etc. Vê-se, portanto, que a organização para qualificar a prática é sustentada por conhecimentos teóricos que devem ser sistematizados por meio de textos específicos para esse fim.

Nessa proposta, ao se tratar da pesquisa como princípio pedagógico, ressalta-se que os textos relacionados à produção de conhecimento envolvem habilidades cognitivas complexas que vão desde a definição do objeto de estudo, a sistematização de teorias do objeto, a organização da metodologia específica para a ação, a descrição dos resultados encontrados, a análise dos dados em relação à teoria escolhida, a reflexão sobre como 
esses resultados se relacionam à realidade investigada, a proposição de soluções e de intervenções etc. Ressalta-se que, para a produção eficaz desses gêneros, é imprescindível que o estudante tenha sido inserido de forma progressiva na leitura e escrita de textos mais basilares voltados à sistematização e à reflexão de conceitos teóricos, desenvolvendo, desse modo, habilidades cognitivas diversas.

Dentro dessa perspectiva, o objeto desta pesquisa é a produção escrita do texto ensaio curto dissertativo ${ }^{1}$ por meio da tecnologia de informação e comunicação, sendo o problema de investigação a competência dos estudantes da Educação Profissional Técnica de Nível Médio para a produção escrita do ensaio dissertativo. A hipótese de pesquisa é a de a competência produtiva do ensaio dissertativo se qualifica à medida que sejam aplicadas estratégias específicas de leitura e escrita. Nessa relação, o objetivo geral da pesquisa é testar estratégias para o desenvolvimento da competência produtiva escrita dissertativa nos sujeitos em investigação. Para dar conta desse propósito, os objetivos específicos são: a) definir as variáveis de investigação; b) diagnosticar a realização das variáveis por meio de préteste; c) elaborar as variáveis de intervenção por meio de leitura e escrita; d) aplicar a intervenção; e) diagnosticar a realização das variáveis no pós-teste e f) relacionar os resultados do pré-teste e pós-teste para medir se ocorreram mudanças nas as variáveis em estudo.

Esta pesquisa, inserida nos pressupostos da Psicolinguística, se justifica pela necessidade de se conhecer de forma mais abrangente o nível de letramento dos sujeitos que adentram nessa modalidade educativa. A seleção desses estudantes ocorre por meio de prova escrita objetiva, sendo que esse exame tem caráter classificatório e não eliminatório, sendo que a seleção obedece aos seguintes critérios:

\footnotetext{
${ }^{1} \mathrm{O}$ termo "ensaio" busca diferenciar o conceito de gênero textual do conceito de tipologia textual dissertação, que predomina neste texto. O termo "texto dissertativo", ainda comumente usado na esfera escolar e nos diferentes exames nacionais não condiz com os atuais pressupostos teóricos, que subsidiam as diretrizes para o ensino de língua, conforme referencial teórico abaixo. Em acréscimo, o termo "curto" é utilizado para distinguir esse gênero textual dos ensaios mais longos elaborados em contextos discursivos originais como o filosófico, o literário etc.
} 
$50 \%$ das vagas para ampla concorrência.

50\% das vagas para o sistema de cotas para Escolas Públicas.

$50 \%$ das vagas para Renda
familiar bruta igual ou inferior a
1,5 salário per capta.

$16 \%$ das vagas para pretos, pardos e índios.

$84 \%$ das vagas para os demais.
$50 \%$ das vagas para renda familiar bruta superior a 1,5 salário per capta.

$16 \%$ das vagas para pretos, pardos e índios.

$84 \%$ das vagas para os demais.

\section{Quadro 1: Distribuição de vagas de acordo com os editais de ingresso}

Fonte: Elaborado pela autora com base na análise os editais de ingresso dos sujeitos investigados

Os dados resultantes desta pesquisa possibilitarão que sejam criados procedimentos didático-pedagógicos mais eficazes para o desenvolvimento do conteúdo proposto nos documentos oficiais para esse nível de educação, de forma a qualificar efetivamente o estudante em todas competências elencadas nesses documentos por meio dos processos discursivos acima destacados.

Para dar conta desse propósito, este artigo se estrutura com os seguintes elementos textuais: na Introdução, apresenta-se o tema, o subtema, o objeto, o problema, a hipótese, o objetivo geral e os objetivos específicos e a justificativa da pesquisa. No Referencial teórico, trata-se dos conceitos teóricos relativos aos aspectos do texto como unidade de ensino e a tecnologia como conteúdo de ensino e aprendizado no processo de escolarização. Na Metodologia, o desenho da pesquisa traz as modalidades de pesquisa, os procedimentos metodológicos e os instrumentos selecionados para seu desenvolvimento. Na Análise dos resultados, apontase alguns dados comparativos entre o pré-teste e pós-teste relacionando-os ao referencial teórico apresentado. Por fim, em Conclusão, retoma-se os resultados e aponta-se a relevância da pesquisa para a qualificação da educação profissional. 


\title{
2 REFERENCIAL TEÓRICO
}

O conteúdo relativo ao referencial teórico está organizado nas seguintes seções: (2.1) O texto como unidade de ensino e aprendizagem e (2.2) A tecnologia digital como conteúdo de ensino e aprendizagem.

\subsection{O texto como unidade de ensino e aprendizagem}

Os documentos norteadores para a qualidade da educação nacional entre os quais estão os Parâmetros Curriculares Nacionais (PCN) para o Ensino Fundamental (BRASIL, 1998) e para o Ensino Médio (BRASIL, 2000) propõem que o processo de ensino e aprendizagem da Língua Portuguesa deve assumir o texto como unidade de ensino, ou seja,

\begin{abstract}
A unidade básica da linguagem verbal é o texto, compreendido como a fala e o discurso que se produz, e a função comunicativa, o principal eixo de sua atualização e a razão do ato linguístico. $\mathrm{O}$ aluno deve ser considerado com o produtor de textos, aquele que pode ser entendido pelos textos que produz e que o constituem como ser humano. $\mathrm{O}$ texto só existe na sociedade e é produto de uma história social e cultural, único em cada contexto, porque marca o [dialogismo] entre os interlocutores que o produzem e entre os outros textos que o compõem. (BRASIL, 2000, p. 18).
\end{abstract}

Vê-se que o texto é a materialidade linguística resultado de processos discursivos que se tipificam pela sua recorrência em determinada esfera social, ou seja, em um contexto discursivo, como por exemplo, cotidiano, religioso, literário, filosófico, jornalístico, político, escolar, científico, etc.

Em acréscimo, um texto pode ser estudado em uma perspectiva social (do discurso) ou por uma perspectiva textual, no contexto verbal. Ao se tratar da linguagem em uma perspectiva social, a corrente bakhtiniana da Análise 
Dialógica do Discurso (ADD) (BAKHTIN, 1981[1929], 2003[1930]) propõe que, a partir da relação bidirecional entre linguagem e sociedade, em um determinado contexto sócio-histórico e cultural, as situações sociais de interação entre indivíduos tipificam-se e, a partir delas, os enunciados que as materializam. Os enunciados, por sua vez, se realizam e se regularizam nas esferas sociais específicas da atividade humana, sendo relativamente estabilizados na forma de gêneros do discurso. Ainda em relação a esses pressupostos teóricos, segundo Bakhtin (2003), a linguagem faz a mediação entre os diferentes campos sociais de interação, em consequência, os usos sociais da linguagem são multiformes e heterogêneos, assim como os são as esferas da atividade e comunicação humanas. Essa mediação é realizada por enunciados (orais ou escritos), concretos, únicos, irrepetíveis e heterogêneos que são proferidos pelos sujeitos atuantes em determinadas situações sociais de interação. Assim, os enunciados refletem as condições sociais e as finalidades de cada esfera e situações sociais, regularizados por meio do tema, composição e estilo (do enunciado) que, em confluência, são indissoluvelmente inter-relacionados e se constituem mutuamente.

Ainda em relação a esse conceito, dentro de uma visão psicolinguística, Schneuwly e Dolz (2010 p. 64) definem o gênero como suporte de uma atividade de linguagem, o qual se estrutura em três dimensões:

a) os conteúdos e os conhecimentos que se tornam dizíveis por meio dele; b) os elementos das estruturas comunicativas e semióticas partilhadas pelos textos reconhecidos como pertencentes ao gênero; e c) as configurações específicas de unidades de linguagem, traços, principalmente, da posição de tipos discursivos que formam sua estrutura. O gênero, assim definido, atravessa a heterogeneidade no uso. São as dimensões partilhadas pelos textos pertencentes ao gênero que Ihe conferem uma estabilidade de fato, o que não exclui evoluções por vezes, importantes.

Nessa perspectiva, o gênero, pela sua relativa estabilidade, constituise "como um modelo comum, como uma representação integrativa" (SCHNEUWLY; DOLZ, 2010 p. 64. Grifos no original) que determina um 
horizonte de expectativas para os membros de uma determinada comunidade em suas práticas de linguagem. Em outras palavras, o que caracteriza, portanto, um gênero é o reconhecimento de uma determinada prática discursiva, em um determinado contexto social, através de seus traços temáticos e composicionais.

Com base no que está exposto acima, reforça-se que o texto é constituído pela sua função social, composicional, temática e estilística. Ao se tratar da função estilística do texto, ou seja, a dimensão textual-linguística, remete-se aos pressupostos teóricos sinalizados pela Linguística Textual. De acordo com Marcuschi (2008, p. 96), os aspectos da textualização são constituídos por um produtor (autor), um leitor (receptor) e um texto (o evento), condição em que o texto é entendido não como um produto acabado, pronto, mas como um processo. No texto como processo e produto, há a situação comunicativa relacionada ao contexto social de produção (contextualidade) que toma por base os seguintes critérios: intencionalidade e aceitabilidade (orientados pelo aspecto psicológico-cognitivo); informatividade (orientado pelo critério computacional-processamento); situacionalidade e intertextualidade (orientados pelo aspecto sócio-discursivo-sociedade). A outra dimensão do texto (cotextualidade) está mais relacionada aos aspectos linguísticos da coesão e da coerência (orientados pelo texto-língua). Neste artigo, em decorrência de seu objetivo, faz-se um recorte desses aspectos de textualização.

Em relação ao aspecto da dialogicidade que caracteriza o texto, a ampliação dos estudos do termo polifonia ${ }^{2}$ realizada por Koch (2008, p. 65), com base em Ducrot (1984), demonstra que há dois tipos de polifonia: a) quando, no mesmo enunciado, há mais de um locutor marcado, corresponderia ao termo intertextualidade explícita e b) quando, no mesmo enunciado, há mais de um enunciador, recobrindo a intertextualidade implícita, porém de uma forma mais ampla, corresponderia à polifonia

\footnotetext{
${ }^{2}$ Sugere-se a leitura de Maingueneau (2001 [1986], 2008 [1998]) que trata de como o ethos ou a interjeição atuam na polifonia.
} 
propriamente dita ${ }^{3}$. Nessa relação, para essa autora, a intertextualidade ${ }^{4}$ se materializa pelo discurso direto, discurso indireto relatado e ou citado, desse modo, diferentes formas de marcar as diferentes vozes no texto.

Dentro desse contexto, ao se tratar no objeto de estudo nesta pesquisa, ou seja, de enunciados que têm por função social sistematizar a prática da pesquisa, ressalta-se que uma das suas principais características é a intertextualidade. Deve-se, por essa razão, indicar as diferentes vozes que constroem esses textos, as quais são marcadas por formas de citações, que, na esfera científica, tais marcações são normatizadas por norma específica ABNT-NBR 10520 (2002). Isso porque ninguém pode se apropriar do patrimônio intelectual alheio, ato esse que, além de ser antiético, é ilegal, já que há uma lei que protege os direitos autorais ${ }^{5}$. Sempre que uma informação de outra pessoa (autor) é trazida para dentro de um texto, essa informação deve ser marcada por elementos específicos. Além do texto, a referência completa do (s) autor (es) deve fazer parte do texto em elaboração. Observase, portanto, que a intertextualidade se relaciona às diferentes vozes do texto, as quais se apresentam de forma explícita, elemento relevante para a construção do sentido no texto, haja vista que um texto sempre é construído por muitas vozes.

Além dos elementos que marcam a intertextualidade, outro aspecto relevante da materialidade textual-linguística, de acordo com as variáveis desta pesquisa, diz respeito à coesão textual, a qual se divide em coesão referencial e coesão sequencial, sendo que tais funções ocorrem com elementos sistêmico-linguísticos específicos para cada fim.

\footnotetext{
${ }^{3}$ Nessa perspectiva, há no mesmo enunciado, a representação de diferentes perspectivas sem a necessidade de utilizar textos efetivamente existentes. A voz do autor do discurso citado não aparece de forma marcada no discurso citante, ou seja, as diferentes perspectivas se enunciam de forma implícita. Há, também aqui, atitudes de adesão ou não do locutor à perspectiva introduzida polifonicamente por ele. A adesão ao discurso do outro pode ocorrer de diversas maneiras entre as quais estão: pressuposição, parafraseamento, argumentos por autoridade etc. $(\mathrm{KOCH}, 2008)$.

${ }^{4}$ Sugere-se a leitura de Koch (2008) para explicações teóricas mais amplas sobre o conceito de intertextualidade.

${ }^{5}$ A consciência do/a estudante para o uso das diferentes formas de marcar as diferentes vozes no texto é um dos aspectos mais relevantes no aprendizado não só para a construção do sentido do texto, mas também por uma questão de ética, já que ninguém pode se apropriar do patrimônio intelectual alheio, ato esse que, além de ser antiético, é ilegal pela lei dos direitos autorais: Lei oํ 9.610, de 19.02.1998.
} 
A coesão referencial ${ }^{6}$ ocorre por meio de formas remissivas referenciais, ou seja, elementos linguísticos constituídos por um núcleo nominal $(\mathrm{KOCH}, 2004$, p.66) como as anáforas associativas, relacionadas às expressões referenciais como as páginas, os capítulos ao nome livro; as anáforas indiretas caracterizam uma relação indireta que se estabelece de forma inferencial, tal como as expressões referenciais as pichações e as gangues, nas quais a relação de sentido depende do conhecimento compartilhado entre os interlocutores, acionado pela inferenciação. Há também as nominalizações, que não ativam um referente específico, mas sim, referentes textuais abstratos como estado, fatos, eventos, atividades etc. Todas formas são, portanto, possibilidade de os referentes serem retomados ao longo do texto.

As formas remissivas referenciais também ocorrem por meio de sinônimos como carro/automóvel; hiperônimos como legume/cenoura; nomes genéricos como geral/ universal); elipses como, por exemplo, - sobre a mesa, apenas uma garrafa. - em que ocorre a omissão do verbo haver etc. (MARCUSCHI, 2008, p.109). Esse autor apresenta também as formas remissivas não referenciais, que são materializadas por constituintes sem núcleo como os artigos, pronomes adjetivos, numerais, pronomes pessoais, pronomes substantivos, advérbios pronominais como aqui, ali, lá etc. Esses constituintes, geralmente, apresentam características morfossintáticas e semânticas semelhantes ao do referente, permitindo apenas a sua reativação, sem possíveis mudanças de sentido pelo uso de diferentes nomes. Eles retomam, assim, referentes previamente introduzidos, estabelecendo uma relação de correferência entre o elemento anafórico e seu antecedente, ou seja, há uma identidade referencial entre a anáfora e seu referente.

A coesão sequencial, por sua vez, ocorre por meio elementos sistêmico-linguísticos que assumem a função de promover as relações lógicas entre as sentenças e períodos construindo os diferentes sentidos

\footnotetext{
${ }^{6}$ Para um entendimento mais amplo do conceito de coesão textual e os aspectos de discursivização dos elementos referenciais, sugere-se a leitura de Valer (2013).
} 
propostos no texto pelo seu produtor. Esses conectivos textuais, de acordo com Koch (2004, p.129) são os articuladores de conteúdo proposicional, articuladores discursivo argumentativos, articuladores com função de organizar o texto, ou seja, denominados de articuladores metalinguísticos, que se dividem em: modalizadores, metacomunicativos, metaenunciativos.

A coesão textual ocorre, portanto, por meio de diversos elementos sistêmico-linguísticos, definidos como elementos referenciais e elementos sequenciais. O primeiro grupo tem a função de retomar uma informação a fim de promover a progressão do referente e, por isso, do tema do texto. O segundo grupo de elementos tem a função de conectar uma informação à outra de forma linear, provendo assim, a ligação entre as frases, os períodos e os tópicos.

Ao se pensar nos textos que materializam a pesquisa como prática social, reforça-se que, no processo de escolarização, a aprendizagem deve ser iniciada pelas estratégias de leitura de textos científicos direcionando-se às estratégias de sistematização da escrita que ocorre por diferentes textos que vão dos mais simples aos mais complexos, envolvendo sempre os aspectos das normatizações para cada texto. Nessa perspectiva, para que o estudante consiga produzir o ensaio faz-se necessário que ele tenha sido inserido primeiramente, no mínimo, aos textos tomada de notas e ou resumo informativo de conteúdo.

O texto tomada de notas também pode ser chamado de fichamento, sendo que nesta proposta pedagógica, esse texto tem por fim inserir os estudantes nas estratégias e técnicas de leitura e, de forma paralela, a sistematização dos conceitos e outros elementos relevantes relativos à pesquisa. As estratégias de leitura (compreensão textual, recuperação de referentes, inferenciação, interpretação e avaliação) são elaboradas pelo Programa Internacional de Avaliação de Estudantes PISA (abreviatura do inglês: Programme for International Student Assessment), as quais são usadas nos testes nacionais e internacionais dos estudantes brasileiros para medir a habilidade de leitura e escrita (VALER, 2013). Nesse processo, após o processo de leitura, inicia-se o processo de escrita em que cada conceito 
destacado no mapa conceitual é apresentado por meio de um tópico frasal e, na sequência, esse tópico é explicado por meio de parafraseamento do conteúdo estudado, sendo que a retextualização pode se dar buscando possíveis respostas às perguntas $O$ quê? Para quê? Por quê? Quem? Quando? Quais? Como? Onde?, entre outros aspectos relativos às estratégias de leitura. Esse conteúdo parafraseado deve ser organizado em períodos em que as relações lógicas são expressas pelos diferentes elementos de coesão (referenciação e sequencialidade), de tal forma que o conteúdo relativo ao tópico frasal forme um parágrafo devidamente estruturado entre 8-12 linhas. Esses saberes são, portanto, a base para o aprendizado do letramento em estudo.

Ainda nessa atividade, destaca-se uma ou mais citações diretas, em que o estudante é levado a compreender a função da citação direta em relação à paráfrase, bem como o significado de plágio no processo de escrita. $\mathrm{Na}$ sequência, em forma de comentários, insere-se o estudante na quinta estratégia de leitura, a avaliação dos aspectos do respectivo processo comunicativo, levando-o a refletir, por meio de seus conhecimentos prévios e novos, a aplicabilidade do conteúdo à sua realidade humana, social, profissional etc. (VALER, 2013). Pode-se também indicar outras obras já estudadas que tratam do mesmo tema, com o objetivo de marcar as relações de convergência e divergências entre esses textos/autores. Além disso, devese destacar a referência do texto-fonte de acordo com as normatizações. Essa prática tem por fim desenvolver-se no estudante o entendimento de como as diferentes vozes se marcam pela paráfrase, citação direta, comentário, relações etc. em que diferentes expressões sistêmico-linguísticas precisam ser acionadas para a construção do sentido. Esse aprendizado é significativo tendo em vista a dificuldade inicial que o aprendiz apresenta em separar o conteúdo pertencente a cada voz, bem como a seleção adequada dos elementos de coesão para organizar o pensamento na modalidade escrita. Esses aspectos textuais e linguísticos são, dessa forma, fundamentais para o letramento relativo ao processo de pesquisa como princípio pedagógico. 
Observa-se que a prática da tomada de nota/fichamento de conceitos teóricos, citações, comentários, relações entre textos, referências etc. dá a sustentação para o aprendizado do resumo informativo de conteúdo. Esse texto tem por fim apresentar uma síntese de um determinado texto-fonte. Nesse sentido, a elaboração desse texto toma por base a aplicação das estratégias de leitura, o destaque da referência do respectivo texto, a organização do mapa conceitual, a explanação dos conceitos e o destaque das citações. Na sequência, inicia-se a produção do resumo com a apresentação da referência do texto; o parágrafo de introdução em que se apresenta o tema e, de forma rápida, os conceitos de que trata o texto e o fechamento do parágrafo. Na sequência, retoma-se cada conceito em diferentes parágrafos, sendo que se coloca dentro do conteúdo organizado em cada tópico frasal a citação direta para dar a comprovação científica ao conteúdo parafraseado, sem a necessidade de chamada de autor já que é o próprio autor que está sendo sintetizado. Apresenta-se entre os tópicos/parágrafos elementos encadeadores com a finalidade de mostrar as relações lógicas entre os conceitos, promovendo a progressão do tema e do texto, sendo que o último parágrafo do resumo é sempre o conteúdo relativo à conclusão do texto-fonte, conforme a tomada de nota. Esses aspectos vão ampliando, desse modo, o conhecimento do conteúdo em estudo, bem como a estruturação da escrita.

A elaboração de resumo contribui em grande escala para a produção de outros textos, entre os quais estão a resenha, diferentes ensaios etc. $O$ gênero textual ensaio curto dissertativo é um gênero escolar-guia ou gênero naturalizado. Para Schneuwly e Dolz (2010, p.66), isso ocorre haja vista o ensaio pertencer ao grupo de textos considerados "autênticos produtos culturais da escola, elaborado como instrumentos para desenvolver e avaliar progressivamente e sistematicamente, as capacidades de escrita dos alunos." [Grifos no original]. Tais textos são deslocados de seu uso real, ou seja, das práticas discursivas reais e passam a ser utilizados como uma representação do real com a finalidade de desenvolver, através das práticas escolares, o pensamento lógico por meio da análise de um tema, podendo ser utilizado, dessa forma, para fins acompanhamento e avaliação de aprendizagem. 
Após a aprendizagem dessas unidades de ensino, torna-se mais fácil o aprendizado do ensaio, sendo que a produção de ensaios dentro de cada unidade curricular promove ganhos aos alunos. Para Bazerman (2005), essa prática de escrita desenvolve mais cedo a habilidade de lidar com aspectos teóricos mais profundos, tornando-os mais seguros para fazer interpretações pessoais sobre diferentes tópicos, bem como para receber comentários ou críticas dos demais estudantes, além de se tornarem mais dispostos a desafiarem a si mesmos, ao professor e aos autores das fontes lidas. Como consequência, com o desenvolvimento dessa prática, seus textos se tornam mais claros, coerentes e convincentes de modo que qualquer leitor possa ter acesso ao conteúdo desenvolvido. Esse fato está confirmado pelas pesquisas apresentadas no relatório do Programa Internacional Avaliação de Estudantes (PISA, 2009), citado por Valer (2013), o qual aponta que as instituições escolares que adotaram os textos com foco na dissertação como práticas escolares alcançam melhores resultados na qualidade de leitura e de escrita dos seus estudantes.

Em conformidade com o que está posto, o gênero textual ensaio dissertativo tem por função o ato pragmático da exposição, da dissertação, ou seja, expor aspectos teóricos sobre determinado tema, desencadeando uma reflexão, fazendo-se uso da forma pronominal se, sem necessariamente apresentar o teor do convencimento tal qual ocorre no ensaio argumentativo (VALER, 2013) e em outros textos de convencimento em que a enunciação é marcada pelas formas eu e nós, O ensaio dissertativo é, por excelência, o texto que desenvolve no produtor estudante a habilidade para escrever sobre um tema, situação em que deverá escolher os subtemas que comporão o processo de escritura. Esses subtemas devem ter uma relação de sentido entre si e organizados em uma ordem lógica para que ocorra a progressão do tema, do texto promovendo a coerência textual. Essa ordem pode ser: a) relevância: do aspecto mais simples ao mais complexo; b) de realização: do primeiro ao último; c) de ordem: do geral para o particular, entre outros. Observa-se, por isso, o cuidado que o produtor deve ter para a elaboração do conteúdo da sua escrita. 
Ao se entender a função social do ensaio dissertativo e a sua utilização como unidade de ensino na esfera escolar, propõe-se, com base nos estudos de Bazerman (2005) e Valer (2013), que os aspectos composicionais desse texto sejam: a) a introdução (primeiro parágrafo): breve apresentação do tema geral e dos subtemas e o fechamento do parágrafo; b) partes do desenvolvimento: retomada de cada subtema apresentado na introdução na mesma sequência em que foram apresentados para manter a progressão do tema e do texto. Cada subtema/conceito deve ser apresentado em parágrafos específicos, deve ser explanado por um tópico frasal e explicado fazendo uso de paráfrases do conteúdo, bem como de citação direta para dar-lhe a comprovação científica e, por fim, o parágrafo deve ser fechado com frase conclusiva; c) reflexão: é relevante que haja um ou mais parágrafos em que o produtor desenvolva uma reflexão teoria-realidade, promovendo a criticidade retomando sempre o enfoque do tema do texto; d) conclusão (último parágrafo): na conclusão, ocorre a retomada sintética do tema, dos conceitos apresentados no texto relacionando-os ao resultado da reflexão e ao propósito da escolha do tema; e) após a finalização do texto, elabora-se o título do texto, o qual deve ser uma síntese do conteúdo de que trata o texto. Em acréscimo, no final do ensaio, coloca-se a referência completa dos textosbase indicados no texto. Observa-se, desse modo, que a ordem lógica das informações e a retomada de cada subtema garantem a progressão temática e textual.

Ressalta-se, pois, a relação intrínseca entre a recepção e a produção. O processo de escrita se inicia pelas estratégias de leitura de diferentes textos e se expande às estratégias de escrita por meio de diferentes textos didáticos que vão dos mais simples aos mais amplos. Os diferentes textos didáticos preparam o produtor-estudante para as práticas sociais de linguagens mais complexas como é o caso dos textos da esfera científica em que, nessa escrita, são ativadas habilidades cognitivas para interpretar teorias, relacionar, analisar, criticar, refletir, rejeitar ideias fechadas, aprender, buscar soluções, propor alternativas para determinadas situações reais etc. 


\subsection{A tecnologia digital como conteúdo de aprendizagem}

Ao discutir as questões que envolvem o domínio das tecnologias digitais de informação e comunicação nas sociedades grafocêntricas, o renomado sociólogo Chartier (2012) pontua que no meio educacional está ocorrendo outro tipo de analfabetismo, o qual está sendo criado na sociedade atual, em decorrência da historicidade no mundo digital. Segundo esse sociólogo, há uma fronteira entre os que estão dentro desse mundo e outros que, por razões econômicas e culturais, ficam de fora, gerando o que ele chama de analfabetismo digital. O acesso ao mundo digital depende de superar muitos obstáculos e fronteiras, os quais iniciam pela possibilidade da compra dos instrumentos e seguem até a capacidade de fazer um bom uso dessas técnicas.

Em relação ao processo de escolarização, Chartier (2012) aponta que essa é outra tarefa dada à escola, ou seja, de ensinar o estudante a aprender a ler e escrever na tela do computador. É nesse sentido que, segundo o autor, a escola pode corrigir desigualdades que nascem na sociedade mesmo no que diz respeito aos meios de acesso à leitura, já que a escola reflete, ao mesmo tempo, as desigualdades presentes na sociedade. Nesse sentido, passa a ser um desafio fundamental que as crianças e adultos possam ter incorporados instrumentos de relação com a cultura escrita e que essas desigualdades sociais deveriam ser consideradas e corrigidas pela escola, pois pode dar aos que estão desprovidos os instrumentos de conhecimento ou de compreensão da cultura escrita.

As políticas públicas relacionadas ao uso das tecnologias no ambiente escolar foram constituídas nos anos 90. A partir desse período, começaram a ser inseridas em leis e documentos norteadores da educação. A inclusão da tecnologia como conteúdo obrigatório nas instituições de ensino está relacionada à necessidade social e cultural da inclusão do estudante nos meios digitais, tal como está explicitado no PCN para o Ensino Médio: 
[...] o acelerado aumento do conhecimento humano, verificado nas últimas décadas, bem como a transformação das experiências em informação ordenada, armazenável, representável em diferentes formas e de fácil recuperação além de seu uso comunitário e da respectiva transferência dessa aquisição a quaisquer distâncias- tornam a informática um elemento do processo de comunicação e, portanto, um código, que se designa com linguagem digital (BRASIL, 2000, p.58).

Tal acesso está amparado pela Lei de Diretrizes e Bases da Educação Nacional (LDB - 9.394/96), em vigor desde 1996, que exige que todas as instituições de ensino tenham implantado o laboratório de informática, com presença de um profissional para o ensino e suporte aos estudantes e professores da instituição.

Nesse sentido, o mesmo PCN reforça que

Ter acesso ou não à informação pode se constituir em elemento de discriminação na nova sociedade que se organiza. O que já se pode constatar, atualmente, é o distanciamento entre os que conhecem e desconhecem o funcionamento dos computadores. [...]. Esse problema deve ser superado através de mudanças nos currículos escolares, que devem desenvolver competências de obtenção e utilização de informações, por meio do computador, e sensibilizar os alunos para a presença de novas tecnologias no cotidiano. [...]. Em síntese, a informática encontra-se presente na nossa vida cotidiana e incluí-la como componente curricular da área de Linguagens, Códigos e suas Tecnologias significa preparar os estudantes para o mundo tecnológico e científico, aproximando a escola do mundo real e contextualizado. (BRASIL, 2000, p. 60-61).

Em acréscimo a esse aspecto, o parecer 09 de 8 de maio de 2001 do Conselho Nacional de Educação trata das Diretrizes Curriculares Nacionais para a formação de professores da Educação Básica em nível superior em cursos de licenciaturas plena (BRASIL, 2001). Esse documento especifica a necessidade de que os futuros professores aprendam a usar os recursos tecnológicos digitais de informação e comunicação para garantir que, no futuro exercício da docência, as práticas escolares sejam mediadas pelas tecnologias. Espera-se que esse saber possa, por consequência, ser transmitido no processo de escolarização. 
Pode-se observar, portanto, a complexidade de fatores envolvidos para o desenvolvimento da competência leitora e produtora por meio das tecnologias digitais no processo de escolarização. É relevante, por isso, que os integrantes do processo educativo estejam conscientes dessa amplitude, a fim de que todos possam se envolver nesse projeto pedagógico, buscando criar condições adequadas para que a lingua(em) assuma seu caráter inter/transdisciplinar conforme aponta o documento Orientações Educacionais Complementares aos Parâmetros Curriculares Nacionais (BRASIL, 2002). As práticas de lingua(gem) devem ocorrer dentro de cada componente curricular ou por meio de diferentes projetos temáticos no contexto educacional, acelerando, pela sua função natural, a qualidade da educação.

\section{METODOLOGIA}

Esta pesquisa com foco na Psicolinguística busca testar estratégias para qualificar a competência escrita em alunos da Educação Profissional Técnica de Nível Médio. O projeto foi lançado na Plataforma Brasil e liberado sob o parecer número 1.164.777. Assim, nesta seção, apresenta-se o desenho da metodologia, tomado da tese de doutorado de Valer (2012), já que a proposta de pesquisa tem o mesmo enfoque psicolinguístico para a elaboração de textos didáticos.

Seleciona-se como pesquisa principal a pesquisa-ação para esta investigação. Essa pesquisa ocorre quando há interesse coletivo na resolução de um problema ou suprimento de uma necessidade. Pesquisadores e participantes tornam-se parceiros no processo da pesquisa (THIOLLENT, 2005). Além da pesquisa principal, faz-se uso de algumas pesquisas secundárias: relativas à natureza e procedimentos para a coleta dos dados são a pesquisa experimental ou de laboratório, pesquisa bibliográfica e pesquisa documental (SEVERINO, 2007). Em relação ao objetivo da investigação, esta pesquisa se caracteriza como pesquisa descritiva (descrição quantitativa por percentual e descrição qualitativa das variáveis dependentes), pesquisa exploratória (variáveis 
extralinguísticas/independentes) e analítica simplificada (resultados em relação ao referencial teórico).

A pesquisa foi realizada na instituição em que esta autora atua como docente, ou seja, IFSC, Campus Florianópolis. Foi desenvolvida em sala de aula e no laboratório de informática, tendo como sujeitos estudantes do Curso de Panificação e Confeitaria do semestre 2014-2, tomando por base três grupos de variáveis.

As variáveis independentes ou extralinguísticas estão relacionadas aos sujeitos investigados (VALER, 2013): a) sexo, b) idade, c) profissão, d) nível de escolarização do estudante, e) nível de escolarização do pai, f) nível de escolarização da mãe, g) tempo de finalização do ensino médio, h) ensino médio (privado ou público), i) sistema de ensino (regular, EJA, outros); j) forma de entrada no processo de seleção (livre concorrência, cotas); k) nota na prova de seleção; $m$ ) domínio da tecnologia para pesquisa; n) domínio da tecnologia para escrita de textos, o) domínio da tecnologia para comunicação (facebook e outros) e p) domínio da tecnologia para extração de textos via internet.

As variáveis dependentes constituem os dados de investigação (VALER, 2013), que nesta pesquisa são aspectos textuais e linguísticos que compõem o ensaio curto dissertativo: a) título do texto; b) parágrafo de introdução com o tema, subtemas e fechamento; c) quantidade de subtemas; d) qualidade dos subtemas desenvolvidos em tópicos; e) parágrafo de conclusão com a retomada do tema e dos subtemas com a reflexão/avaliação; f) elementos de coesão referencial; g) elementos de coesão de sequencialidade; h) pessoa do discurso, i) marcas da intertextualidade e j) quantidade de linhas. A avaliação de cada uma das variáveis dependentes para análise dos textos foi realizada a partir de três categorias de escolha: alternativa (A) refere-se ao uso adequado de determinado elemento linguístico ou textual em um determinado contexto, em que seu uso é esperado. A alternativa $(B)$ diz respeito ao uso inadequado de determinado elemento linguístico ou textual em um determinado contexto, em que seu uso é esperado, já a alternativa (C) aponta a inexistência ou inadequações extremas de determinado elemento linguístico ou textual em 
um determinado contexto, em que seu uso é esperado. Ressalta-se, aqui, que nosso objeto de estudo trata de texto escrito na variedade entendida como padrão, ou seja, as regras seguem a cultura da escrita em textos que circulam socialmente como é o caso dos textos que circulam na esfera social acadêmica.

Por fim, as variáveis intervenientes (VALER, 2013) estão relacionadas às atividades desenvolvidas no decorrer da investigação com a finalidade de ampliar no estudante a sua competência para a produção do texto em estudo. As estratégias de leitura para o desenvolvimento do esquema cognitivo sobre o tema tomaram por base quatro textos: a) textofonte 1: excerto de ensaio dissertativo elaborado por esta pesquisadora sobre aspectos das modalidade oral; b) texto-fonte 2 : resumo informativo, elaborado por esta pesquisadora de um artigo científico sobre o tema símbolos de informação pública; c) texto-fonte 3: coluna jornalística sobre expressões corporais; d) texto-fonte 4: entrevista jornalística sobre as diferentes formas de comunicação no contexto profissional. Já as estratégias de escrita foram desenvolvidas por meio da leitura, análise da função sociodiscursiva, da composição, do tema, do estilo linguístico e da produção textual dos seguintes textos: tomadas de notas/fichamento de conceitos sobre tema em estudo; resumo informativo de conteúdo e ensaio curto dissertativo.

Reforça-se que o tema escolhido para a produção do ensaio está relacionado ao objeto de ensino e aprendizagem do componente curricular de Linguagem e Comunicação, dentro do qual esta pesquisa se realiza. De acordo com os preceitos teóricos selecionados nesta pesquisa, a qualificação da prática ocorre pela qualificação teórica. Nesse sentido, os conceitos teóricos devidamente sistematizados das diferentes formas de comunicação (símbolos de informação pública, expressão corporal, a oralidade no contexto profissional, a escrita no contexto profissional) são retomados no decorrer das práticas discursivas para a devida reflexão teoria-prática seja dos próprios estudantes pelas simulações em sala de aula ou laboratório, práticas profissionais, no decorrer do estágio ou ainda em situações de observações durante visitas técnicas, simulações etc. Nessas situações, o estudante desenvolve a percepção para relacionar o conteúdo teórico para se preparar 
adequadamente para o processo comunicativo, bem como deve ser avaliar a si e ao outro, ampliando, dessa forma, o objeto em estudo por meio do desenvolvimento teórico aplicado à prática.

Os instrumentos de pesquisa utilizados para esta ação foram: a) questionário ${ }^{7}$ para colher as variáveis independentes relativas aos sujeitos pesquisas, conforme estão descritas acima e b) teste para medir as variáveis dependentes no pré-teste e no pós-teste.

\section{ANÁLISE DOS RESULTADOS}

Em decorrência da grande quantidade de elementos da pesquisaação, não estão apresentados aqui todos os dados relativos à aplicação da pesquisa com a descrição e análise dos resultados do pré-teste e pós-teste, os quais se encontram registrados em relatório de pesquisa. Apresenta-se, assim, apenas alguns dados comparativos entre os dois momentos diagnosticados e a análise com base no referencial teórico como segue.

Para o desenvolvimento desta pesquisa, cujo fim era o de testar estratégias para a qualificação da escrita dissertativa, cada aluno recebeu em sala de aula cópias dos textos sobre o tema, os quais foram lidos individualmente em sala de aula, podendo serem lidos novamente extraclasse. $\mathrm{Na}$ aula subsequente, aplicou-se o pré-teste para o diagnóstico das variáveis dependentes e o questionário para o diagnóstico das variáveis independentes. Buscou-se verificar por meio do questionário como os sujeitos lidavam com a tecnologia para a pesquisa e escrita de textos. Os resultados das variáveis independentes indicam que entre os dezesseis sujeitos investigados, os sujeitos S1, S2, S4, S10, S11, S12, S13 e S16 informaram que, em termos gerais, apresentavam dificuldade com a tecnologia, enquanto S3, S5, S6, S7, S8, S9, S14 e S15 informaram ter domínio da tecnologia. Os

\footnotetext{
${ }^{7}$ De acordo com Marconi e Lakatos (2011b, p. 111) e Severino (2007, p.125), o questionário é constituído por uma série de perguntas que devem ser respondidas por escrito, podendo ser elaborado com perguntas fechadas, cujas respostas são de assinalar, como sim - não ou algo parecido. Já o teste é um instrumento utilizados com a finalidade de obter dados que permitam medir o rendimento, a frequência, a capacidade ou a conduta de indivíduos, de forma quantitativa.
} 
dados apontam também que 9 (56\%) usam pouco a tecnologia para pesquisa na internet; 9 (56\%) a usam para a extração de texto da internet e 8 (50\%) a usam para a escrita. Esses dados reforçam os pressupostos de que uma sociedade grafocêntrica em que praticamente todo o conhecimento elaborado circula por meio da escrita, o advento das Novas Tecnologias de Inovação e Comunicação (TIC), como apresentado em BRASIL (2000) e Chartier (2012) pontua para o papel da instituição de ensino como agência mediadora desse conhecimento. Isso porque a inclusão digital tem se constituído base para a formação cidadã, bem como para a formação profissional, tendo em vista que elas estão cada vez mais presentes nas práticas do mundo do trabalho.

Após a aplicação do pré-teste e do questionário para medir as variáveis independentes, iniciou-se a atividade de pesquisa. Assim, em sala de aula, após a explanação por parte do professor-pesquisador, das estratégias de leitura aplicadas a cada diferente texto-base, por meio de leitura dirigida, os sujeitos organizaram o mapa conceitual com foco no objeto de estudo que são as variáveis de comunicação. Na sequência, ainda em sala de aula, os sujeitos foram inseridos na aprendizagem do texto tomada de notas, cujos conceitos foram elaborados de forma manuscrita, sendo recolhidos para a primeira avaliação e, posterior, reescrita por meio digital.

Nessa mesma relação, ao se tratar da inserção do estudante no letramento, a produção dos gêneros discursivos/textuais na escolarização passou por uma grande mudança, tendo em vista que os textos que circulam socialmente são elaborados por meio da tecnologia. Aspectos relativos à formatação fazem parte da constituição dos textos, como por exemplo, as normatizações do Manual da Presidência da República para os textos da redação técnica da esfera pública (leis, editais, correspondências etc.) e as normatizações da ABNT para a redação da esfera científica. Essas normatizações são um reflexo dessas mudanças, conforme esclarece Rojo (2013, p. 8), "se os textos da contemporaneidade mudaram, as competências/capacidades de leitura e produção de textos exigidas para participar de práticas de letramento atuais não podem ser as mesmas". Para isso, os professores devem desbravar com os estudantes, além das estratégias e práticas complexas de leitura e escrita já discutidas 
anteriormente, também aquelas relacionadas ao ciberespaço, especialmente, com os/as excluídos digitais já em suas práticas cotidianas. Esses aspectos apontam, dessa forma, para novos procedimentos pedagógicos no processo de escolarização.

Com base nesses pressupostos, após a primeira avaliação das tomadas de notas, reservou-se duas aulas no laboratório de informática para que os estudantes digitassem as suas tomadas de notas. Em uma terceira aula no laboratório de informática , os sujeitos produziram individualmente um pequeno resumo informativo de um texto-fonte, cujos conceitos já haviam sido sistematizados por meio da tomada de nota. Após a escrita da tomada de nota e do resumo informativo, os sujeitos foram inseridos ao aprendizado da unidade de ensino ensaio curto dissertativo em que, por meio de leitura e análise de um exemplo desse texto, foram destacados os aspectos da função social, da composição, do tema e do estilo de linguagem que constituem esse texto. Na sequência, no laboratório de informática, aplicou-se o pós-teste, ou seja, nova escrita do ensaio dissertativo com o mesmo comando utilizado quando da aplicação do pré-teste.

A tabela 1 traz os dados comparativos do pré-teste e do pós-teste em relação à realização das variáveis dependentes na turma.

\begin{tabular}{|c|c|c|c|c|c|c|c|c|c|c|}
\hline Sujeitos & V1 & V2 & V3 & V4 & V5 & V6 & V7 & V8 & V9 & V10 \\
\hline \multicolumn{11}{|c|}{$\begin{array}{l}\text { Pré-teste } \\
\text { Pontuação esperada por variável por aluno: } 32=100 \% \\
\text { Pontuação esperada na turma: } 320=100 \% \\
\text { Pontuação realizada pela turma: } 115=36 \%\end{array}$} \\
\hline $16=100 \%$ & $\begin{array}{l}3- \\
9 \%\end{array}$ & $\begin{array}{l}8- \\
24 \%\end{array}$ & $\begin{array}{l}16- \\
50 \%\end{array}$ & $\begin{array}{l}16- \\
50 \%\end{array}$ & $\begin{array}{l}11- \\
34 \%\end{array}$ & $\begin{array}{l}16- \\
50 \%\end{array}$ & $\begin{array}{l}16- \\
50 \%\end{array}$ & $\begin{array}{l}9- \\
25 \%\end{array}$ & $\begin{array}{l}1- \\
3 \%\end{array}$ & $\begin{array}{l}19- \\
60 \%\end{array}$ \\
\hline \multicolumn{11}{|c|}{$\begin{array}{l}\text { Pós-teste } \\
\text { Pontuação esperada por variável por aluno: } 20=100 \% \text { - } \\
\text { Pontuação esperada na turma: } 200=100 \% \\
\text { Pontuação realizada pela turma: } 192=96 \%\end{array}$} \\
\hline $10=100 \%$ & $\begin{array}{l}20- \\
100 \\
\%\end{array}$ & $\begin{array}{l}19- \\
95 \%\end{array}$ & $\begin{array}{l}20- \\
100 \%\end{array}$ & $\begin{array}{l}20- \\
100 \\
\%\end{array}$ & $\begin{array}{l}19- \\
95 \%\end{array}$ & $\begin{array}{l}16- \\
80 \%\end{array}$ & $\begin{array}{l}19- \\
95 \%\end{array}$ & $\begin{array}{l}20- \\
100 \\
\%\end{array}$ & $\begin{array}{l}20- \\
100 \\
\%\end{array}$ & $\begin{array}{l}19- \\
95 \%\end{array}$ \\
\hline
\end{tabular}

Legenda: (1) Título do texto; Var. (2) Parágrafo de introdução com tema e subtemas; Var. (3) Quantidade de subtemas: cinco; Var. (4) Qualidade dos subtemas; Var. (5) Parágrafo de conclusão; Var. (6) Elementos de coesão 
referencial; Var. (7) Elementos de coesão sequencial; Var. (8) Forma pronominal (Se); Var. (9) Intertextualidade; Var. (10) Quantidade de linhas.

Fonte: Elaborado pela autora com base na análise os editais de ingresso dos sujeitos investigados

Ao se analisar os dados do pós-teste, o primeiro aspecto que se deseja apontar é o fato de que o pré-teste foi realizado, de forma manuscrita, por dezesseis sujeitos, já o pós-teste foi realizado, por meio digital, por dez sujeitos. Os dados revelam que, em relação às diferentes variáveis dependentes, no pré-teste a turma realizou cento e quinze pontos (115 = $36 \%)$ em relação aos trezentos e vinte $(320=100 \%)$ esperados. Já no pósteste, a turma realizou cento e noventa e dois pontos $(192=96 \%)$ dos duzentos $(200=100 \%)$ esperados, já que dez estudantes o realizaram.

Ao se tratar das variáveis destacadas para análise, pode-se dividi-las em dois grupos: o primeiro relaciona-se mais propriamente aos elementos textuais que compõem o ensaio e o segundo grupo se relaciona aos elementos sistêmico-linguísticos que subsidiam a textualização.

No que diz respeito à realização da variável (1), título do texto (3 = $9 \%$ no pré-teste versus $20=100 \%$ no pós-teste) indica que os sujeitos compreenderam que ao produzirem um texto com a sua própria voz, o título constitui-se um elemento obrigatório, o qual tem por fim apresentar uma síntese do conteúdo de que trata o texto. Já a realização da variável (2), parágrafo de introdução com tema e subtemas $(8=24 \%$ no pré-teste versus $19=95 \%$ ) demonstra que os sujeitos ampliaram em grande escala a consciência da função e dos elementos que constituem esse parágrafo inicial do texto em análise.

No que diz respeito à realização da variável (3), quantidade de subtemas ( $16=50 \%$ no pré-teste versus $20=100 \%$ no pós-teste), revela 0 desenvolvimento da consciência de cada sujeito em relação aos diferentes subtemas presentes nos textos lidos, os quais estão relacionados ao tema que trata das diferentes formas de comunicação. A realização da variável (4), qualidade dos subtemas ( $16=50 \%$ no pré-teste versus $20=100 \%$ no pósteste) está diretamente relacionada à habilidade de o sujeito trazer para o seu 
texto o conteúdo parafraseado de cada conceito lido em diferentes textosfonte. Pode-se relacionar a essas duas variáveis, a variável (10), quantidade de linhas (19 = 60\% no pré-teste versus $19=95 \%$ no pós-teste), cuja realização também apresentou qualificação. Ressalta-se que a quantidade de linhas nem sempre condiz com a qualidade do texto, isso porque é comum que a textualização ocorra com informações desconectadas do conteúdo dos textos- base propostos para a escrita quando o produtor não conseguir desenvolver uma boa sistematização dos conceitos propostos. Há também o caso em que as informações aparecem de forma circular sem que haja a progressão do tema e do texto. Esse aspecto é consequência da falta de consciência da função dos tópicos frasais para sustentar a organização dos parágrafos e dar progressão ao tema e ao texto.

A variável (5), conclusão do texto $(11=34 \%$ no pré-teste versus $19=$ $95 \%$ no pós-teste), propunha que o produtor retomasse sinteticamente os conceitos e os relacionasse à sua realidade. Na sequência, traz-se um exemplo desse elemento textual, extraído do texto de S11:

Dessa forma, a competência linguística ocorre quando o falante da língua materna tem o domínio dos aspectos específicos que caracterizam a comunicação não-verbal, a comunicação verbal oral e a comunicação verbal escrita em cada contexto comunicativo. Esse fato mostra que se deve ter conhecimento do significado dos principais símbolos de comunicação não-verbais como placas de indicação de banheiro, tipos de lixeira, placas de segurança entre outros. Além disso, é preciso também ficar atento às expressões corporais e faciais do cliente para saber se ele está entendo a mensagem que se está transmitindo ou se sua expressão facial indica satisfação com o produto. Como se observa, a comunicação oral depende das variações linguísticas de cada região ou de cada grupo específico, haja vista que isso acontece constantemente no dia a dia. É importante ter-se consciência dessas variações linguísticas na forma de falar das pessoas e do uso estilo informal usado na comunicação oral, pois, na vida profissional, lida-se com pessoas de todas as idades, localidades, sexo, de todos os níveis sociais e grau de escolaridade quando se lida diretamente com o cliente no atendimento no balcão, no caixa, no telefone. Também se deve ter conhecimento de que a língua escrita exige mais atenção quanto à formalidade e às regras gramaticais. No contexto profissional, é preciso sempre observar também a maneira formal da escrita que deve ser 
sempre de acordo com as regras gramaticais quando são elaborados cardápios, receitas, fichas técnicas, comandas, notas fiscais, avisos postados em murais, e-mails, pedidos, rótulos e embalagens, entre outros. Conclui-se que a comunicação no contexto profissional, tanto na forma não verbal, como na forma oral e na forma escrita, deve ser valorizada e usada corretamente, sendo encarada como um recurso necessário para um bom entendimento das mensagens e, consequentemente, um bom diálogo e um bom andamento do trabalho. Ressalta-se ainda a necessidade de um conhecimento prévio sobre as formas e ferramentas de comunicação para que se atinja o objetivo de transmitir a mensagem de maneira correta facilitando o seu entendimento por todos, sendo que todos esses aspectos qualificam o profissional e o contexto em que ele esteja inserido. Enfim, a comunicação no contexto profissional deve ser valorizada, tornando-se um recurso necessário para que haja entendimento entre os colegas de trabalho, sendo que os meios ofertados para a comunicação vêm enriquecendo cada vez mais o meio profissional, fazendo com que o ouvinte e o locutor caminhem juntos para os objetivos propostos por cada um em relação aos produtos e serviços relativos à área de panificação e confeitaria.

Pelo fragmento do texto, pode-se observar que o sujeito retoma os conceitos abordados teoricamente no decorrer do ensaio, fazendo de elementos de coesão de retomada e de sequencialidade, e os relaciona à sua realidade, demonstrando a relevância desse conhecimento para a qualificação pessoal e profissional. A descrição qualitativa dos dados indica que a maior parte dos estudantes promoveu essa relação, conforme propõe a função sociodiscursiva do ensaio.

Ao se tratar do segundo grupo, observa-se que todas as variáveis tiveram uma pontuação maior após o processo de intervenção: a variável (6), elementos de coesão referencial passou de $16=50 \%$ no pré-teste para $16=$ $80 \%$ no pós-teste; a variável (7), elementos de coesão sequencial passou de $16=50 \%$ no pré-teste para $19=95 \%$ no pós-teste. Como ressaltado no referencial teórico, o uso dos elementos de coesão é de fundamental importância para que as relações lógicas entre os períodos e os parágrafos sejam adequadamente demonstradas, além da sua relevância para o processo de retomada do referente promovendo a progressão do tema e do texto. Já a variável (8), forma pronominal Se passou de $9=25 \%$ no pré-teste 
para $20=100 \%$ no pós-teste. A qualificação em relação ao uso dessa variável indica que os sujeitos se tornaram mais conscientes da função das formas de enunciação de acordo com as diferentes finalidades discursivas, as quais são materializadas por diferentes textos em diferentes esferas sociais. No excerto do texto do sujeito $\mathbf{S 1 1}$, conforme apresentado acima, estão sublinhadas algumas realizações dessas variáveis, por meio das quais, pode-se observar a sua relevância para a construção de sentido no texto.

Por fim, ainda dentro desse grupo, os dados indicam que a variável (9), intertextualidade teve o maior aumento na pontuação passando de $1=$ $3 \%$ ) no pré-teste para $20=100 \%$ no pós-teste. Ressalta-se que a variável intertextualidade, como apontado por Valer (2013), é de fundamental importância para a qualidade de leitura e escrita. Em especial, a textualização da redação científica se constitui por muitas diferentes vozes, as quais devem ser adequadamente marcadas de acordo com as normatizações propostas, a fim de que o leitor consiga acompanhar a teorização. Devem também ser apresentadas as fontes consultadas para que o leitor também possa acessar tal conteúdo teórico, ressaltando-se, por fim, o aspecto dos direitos autorais, conforme apontado no referencial teórico.

Ao se tratar do processo de escrita, de acordo com Schneuwly e Dolz (2010, p. 66), o gênero textual ensaio curto dissertativo proporciona ao seu produtor o desenvolvimento do pensamento lógico e a análise teórica de um tema e subtemas inseridos na realidade do seu entorno sócio-histórico e cultural, sendo neste contexto de pesquisa, o contexto profissional. Os dados indicam que a maior parte dos estudantes promoveu essa relação, conforme propõe a função sociodiscursiva do ensaio, confirmando a proposição de Bazerman (2005), ao afirmar que a produção de ensaios dentro dos diferentes componentes curriculares amplia a prática para promover relações conceituais mais profundas, qualificando a escrita, deixando os textos mais coerentes e convincentes.

O desenvolvimento do conteúdo para a produção do ensaio se dá por meio da prática do texto tomada de notas e resumo informativo de conteúdo, momento em que o estudante aprende efetivamente as estratégias de leitura 
(VALER, 2013) de diferentes textos, sistematizando diferentes conceitos teóricos. Com essa prática, o estudante começa a perceber que a escrita se torna mais fácil por ele já ter organizado o conteúdo para a produção do seu próprio texto, o qual passa a ser mais longo, pois ele tem o que dizer sobre o tema em estudo; passa a usar de forma mais consciente os elementos coesão referencial e sequencial para relacionar os conceitos teóricos entre si, promovendo a progressão do tema e do texto.

A tabela (2) traz os dados comparativos do pré-teste e do pós-teste da realização das variáveis dependentes por pontuação por cada aluno da turma. Retoma-se que, no pré-teste 16 sujeitos produziram o texto e no pósteste 6 não o produziram (NP). Ressalta-se que entre os oito sujeitos que declararam ter dificuldade para o uso da tecnologia, cinco deles (S1, S4, S10, S12, S16) não finalizaram todas as atividades pedagógicas propostas para o teste. Por outro lado, entre os sujeitos que se declararam capazes para o uso da tecnologia, apenas S14 não concluiu as atividades propostas para o teste.

Tabela 2: Dados comparativos (pareados por pontuação) do pré-teste e do pósteste das variáveis dependentes por sujeito

\begin{tabular}{|c|c|c|c|c|c|c|c|c|c|c|c|c|c|c|c|c|}
\hline S1 & S2 & S3 & S4 & S5 & S6 & S7 & S8 & S9 & $\begin{array}{l}\mathrm{S} 1 \\
0\end{array}$ & $\begin{array}{l}\text { S1 } \\
1\end{array}$ & $\begin{array}{l}\mathrm{S} 1 \\
2\end{array}$ & $\begin{array}{l}\text { S1 } \\
3\end{array}$ & $\begin{array}{l}\mathrm{S} 1 \\
4\end{array}$ & $\begin{array}{l}\mathrm{S} 1 \\
5\end{array}$ & $\begin{array}{l}\text { S1 } \\
6\end{array}$ & Total \\
\hline
\end{tabular}

\section{Realização por pontuação das variáveis no pré-teste}

\begin{tabular}{l|l|l|l|l|l|l|l|l|l|l|l|l|l|l|l|l}
\hline 7 & 6 & 9 & 6 & 13 & 5 & 7 & 12 & 9 & 8 & 8 & 8 & 0 & 9 & 1 & 7 & $115=36 \%$ \\
\hline
\end{tabular}

Realização por pontuação das variáveis no pós-teste

\begin{tabular}{l|l|l|l|l|l|l|l|l|l|l|l|l|l|l|l|l}
\hline NP & 19 & 19 & NP & 15 & 19 & 20 & 20 & 20 & NP & 20 & NP & 20 & NP & 20 & NP & $192=92 \%$ \\
\hline
\end{tabular}

Fonte: Elaborado pela autora com base na análise os editais de ingresso dos sujeitos investigados

Em relação aos resultados das variáveis dependentes no pré-teste, observa-se que S5 e S12 atingiram mais de 50\% dos pontos, sendo que o 
primeiro pontuou treze $(13=65 \%)$ e o segundo pontuou doze $(12=60 \%)$ dos vinte pontos por sujeito em um total de dez variáveis. Isso significa dizer que tanto os sujeitos ingressantes por livre concorrência como os ingressantes por cotas apresentam pouco conhecimento para o uso das variáveis em estudo. A descrição qualitativa dos textos demonstra que a maioria dos sujeitos não conseguiu manter em foco o tema e os subtemas de forma a parafrasear o conteúdo apresentado pelos autores. Em geral, o sujeito apresenta o subtema e, ao tentar ampliá-lo o faz adicionando informações do senso comum, do seu conhecimento do dia a dia. Esse aspecto revela a dificuldade de o sujeito extrair dos textos lidos as informações relevantes para cada conceito e a dificuldade de sistematizar o conteúdo lido por meio de paráfrases, atividades que devem ser desenvolvidas pela prática do texto tomada de notas.

Os dados da tabela acima indicam que todos os alunos que realizam o pós-teste qualificaram consideravelmente a realização dessas e das demais variáveis que fazem parte da escrita do ensaio dissertativo. Destaca-se que o sujeito S5 foi quem teve maior pontuação no pré-teste, treze (13) pontos, porém optou por manter uma única versão do texto no pós-teste, no qual realizou quinze (15) pontos, ou seja, foi o texto com menor índice de pontuação no pós-teste. O sujeito S5 é graduado e pela sua profissão mantém o hábito de leitura, mas, pelos dados, observa-se que, embora ele tenha acompanhado todo o processo de intervenção, desenvolvendo as atividades de leitura e escrita propostas, alguns aspectos relativos aos elementos do texto em si deixaram de ser qualificados.

Com procedimentos diferentes do sujeito $S 5$, que não realizou a reescrita do texto, o sujeito $\mathrm{S} 13$ fez cinco versões de seu texto e com esse procedimento atingiu a pontuação máxima (20) no pós-teste. De forma semelhante, os sujeitos S3 e S11 qualificaram a sua produção textual com quatro versões; os sujeitos S6, S7 e S15 com três versões; já os sujeitos S2, S8 e S9 com duas versões. Esse procedimento didático toma por base os pressupostos psicolinguísticos, sendo que o processo de revisão, de acordo com Gombert (1992, 1993, 2003) demanda que os escritores dominem as regras da grafia, a escolha das palavras, a concordância morfossintática, a 
pontuação, além dos elementos para a coesão e a coerência do texto, a formatação, a sequência textual predominante, a composição do texto e os fatores pragmáticos que o caracterizam. Isso para que o texto esteja pronto para circular socialmente, de acordo com as normatizações de cada gênero textual dentro de cada esfera social de produção. Segundo o autor, o ato de ensinar o aprendiz a refletir sobre os elementos da escrita é pouco ensinado na escola, tornando-se cada vez mais difícil substituir o ato epiprocedural (automático) pelo ato de reflexão e avaliação sobre a escrita (metalinguagem e metatextualização). Dessa forma, reforça-se a relevância de tornar 0 processo de aprendizagem uma ação mais ampla no que se refere à consciência dos aspectos que envolvem a escrita.

De forma paralela, acentua-se a necessidade da mediação ampla, conforme os pressupostos sociointercionistas de Vygotsky (2008 [1930]), para o desenvolvimento de processos cognitivos complexos, os quais se constituem por meio da linguagem. Em outras palavras, a ampliação e a qualificação do pensamento se dá pela linguagem mediada socialmente, a qual se materializa por meio de textos que se tipificam em diferentes esferas sociais. Nessa relação, os agentes da educação devem atentar para que o estudante desenvolva a consciência da função social do texto, bem como dos diversos elementos textuais, linguísticos além do conteúdo temático que envolve cada produção textual, entendendo-se, conforme os PCNs (1998, 2000), que a atividade de escrita é um ato por natureza complexo, por isso simplificá-lo no processo de escolarização, é ignorar o verdadeiro papel da escola. Reforça-se, desse modo, a função da língua (gem) para o desenvolvimento cognitivo do ser humano e a função da lingua(gem) para a cidadania e a inclusão social.

Retoma-se, aqui, as diretrizes para a Educação Profissional Técnica de Nível Médio (BRASIL 2012a; BRASIL, 2012b) em que essa modalidade de ensino deve capacitar o aluno com conhecimentos teóricos para a qualificação das práticas nas diversas atividades do setor produtivo. Em acréscimo, ao se tratar dessa modalidade de educação, reforça-se a relevância da pesquisa como o princípio pedagógico conforme pontuado no documento que trata das diretrizes gerais para a educação básica dentro da 
qual está a educação profissional (BRASIL, 2013). O desenvolvimento da habilidade de leitura e escrita da teoria deve ocorrer por meio de diferentes textos que circulam socialmente, sendo que, no processo de ensino e aprendizagem, o texto passa a ser a unidade de ensino conforme as diretrizes para o ensino da linguagem (BRASIL 1998, BRASIL, 2000, BRASIL, 2002). Aponta-se, portanto, o papel social das instituições de ensino para a qualificação da educação em qualquer que seja a modalidade em curso.

Em relação ao uso da tecnologia para a escrita dos textos didáticos, ressalta-se que, embora tenha sido reservada determinada carga horária para esse fim, observou-se que vários estudantes apresentavam muita dificuldade para o manuseio da tecnologia, desde para ligar/desligar o computador até o ato de digitar um texto com os respectivos recursos, bem como para salvá-lo em arquivos específicos que que esses conteúdos pudessem ser retomados posteriormente para os outros procedimentos pedagógicos. Nesse sentido, muitos estudantes não conseguiram transformar o conteúdo sistematizado em sala de aula na forma manuscrita e avaliado na primeira versão em texto digital para o processo de escrita e reescrita das tomadas de notas de conceitos e dos demais textos, já que o foco dessa atividade era justamente mostrar a relevância da sistematização de conceitos para (re)utilizá-los em diferentes textos didáticos e científicos, sendo que, para esse fim, torna-se fundamental que o conteúdo esteja digitado e salvo de forma segura para a sua retomada.

Esse dado relativo à tecnologia é preocupante, haja vista que conforme o PCN (BRASIL, 1998), a linguagem não pode estar dissociada do uso da tecnologia para a leitura e escrita, habilidade essa que deve ser desenvolvida plenamente ainda no ensino fundamental. Nessa mesma direção, o PCN (BRASIL, 2000) para o Ensino Médio ratifica a relação entre tecnologia - ensino e aprendizagem - inclusão social - ciência. $O$ documento acentua a relevância de as instituições de ensino assumirem a responsabilidade de inserir o ensino de informática como conteúdo de Língua Portuguesa. Esse aspecto também é ressaltado por Chartier (2012), para quem a falta de domínio da tecnologia para a leitura e escrita promove o analfabetismo digital, impedido que os sujeitos acessem os bens culturais a 
sua volta. Esse fato se refletiu nos dados encontrados, já que muitos dos sujeitos sem acesso adequado à tecnologia não conseguiram avançar no processo de aprendizagem das unidades de ensino em estudo.

Ao se retomar os propósitos desta pesquisa, vê-se que os resultados dos dados confirmam os pressupostos de que a competência produtiva do ensaio dissertativo se qualifica à medida que são aplicadas estratégias específicas de leitura e escrita. De forma paralela, o objetivo principal desta pesquisa também foi atingido, o qual buscava testar estratégias para a ampliação da qualidade da escrita dissertativa por meio da unidade de ensino ensaio curto dissertativo com estudantes da Educação Profissional Técnica de Nível Médio. O aumento considerável do índice de realização das variáveis dependentes no pós-teste atesta que as variáveis intervenientes selecionadas para o ensino e os procedimentos didático-pedagógicos adotados desenvolveram nos sujeitos que realizam as atividades a aprendizagem proposta nesta atividade de aprendizagem.

Certamente a atividade textual proposta nesta pesquisa é de fundamental importância para que os estudantes desenvolvam a consciência para o uso dos elementos textuais e linguísticos necessários à organização do pensamento a fim de promover relações teóricas, ampliar a criticidade em relação à própria teoria ou à realidade em que está inserido, planejar e avaliar ações nos diferentes contextos em que atua etc. No processo de escolarização, os textos didáticos e científicos devem ser utilizados pela comunidade escolar como ferramenta pedagógica para avaliar o aprendizado de determinadas habilidades cognitivas dos estudantes, substituindo de forma substancial o gênero prova em que, na maioria das vezes, leva o estudante a um exercício de memorização momentânea sem o desenvolvimento de habilidades cognitivas para a reflexão, avaliação, relação, análise, criticidade etc. Dessa forma, são esses gêneros textuais que desenvolvem nos estudantes de maneira mais acentuada a compreensão da teoria e do funcionamento de uma determinada realidade, criando as condições necessárias ao deslocamento constante da realidade em que estão inseridos. 


\section{CONSIDERAÇÕES FINAIS}

Esta pesquisa aplicada a um grupo de sujeitos de um curso da modalidade da Educação Profissional Técnica de Nível Médio buscou testar estratégias para a ampliação da competência da produção escrita dissertativa, por meio da unidade de ensino ensaio curto dissertativo, fazendo uso da tecnologia digital. Para esse fim, fez-se uso da modalidade da pesquisa-ação, com diferentes grupos de variáveis, sendo que os principais instrumentos de pesquisa foram o teste e o questionário.

A análise dos dados das variáveis independentes demonstrou que o perfil dos sujeitos pesquisados se caracteriza pela heterogeneidade em relação à: a) tempo fora da escola; b) domínio e/ou acesso à tecnologia para leitura e escrita; c) trabalho no contra turno; d) diferentes níveis de escolarização entre outros. Em relação aos dados das variáveis dependentes, observou-se que os sujeitos que produziram os textos didáticos tomada de nota e resumo informativo, apesar dos diferentes perfis que os caracterizam, apresentam condições para o aprendizado do texto didático ensaio curto dissertativo. Em relação ao uso da tecnologia digital para a produção e circulação do conhecimento, configurou-se uma lacuna no desenvolvimento das atividades propostas. $O$ fato de alguns sujeitos serem inseridos no curso técnico sem nenhuma noção de escrita digital impossibilitou que a escrita dos textos mais longos ocorresse dentro do prazo proposto para esse fim. Diante dessa realidade, faz necessário repensar a educação para a formação geral, bem como a educação para a qualificação profissional e a função do ensino de línguas, levando em consideração as TIC como ponto central para a pesquisa, a escrita e a socialização do conhecimento e, consequentemente, o alargamento do pensamento constituído pela linguagem.

Ressalta-se mais uma vez que a aprendizagem desses textos didáticos, produzidos via tecnologia digital, promove ganhos nos estudantes, preparando-os para a escrita de outros textos, cuja função sociodiscursiva busca relacionar conceitos teóricos em si e ou relacionados à prática, entre os quais estão o ensaio argumentativo, a resenha, o projeto, o relatório etc. 
Essa forma de redação auxilia os estudantes também na elaboração dos textos de redação técnica, além dos textos específicos do contexto profissional.

Por fim, aponta-se a necessidade de que mais pesquisas aplicadas sejam desenvolvidas no processo de ensino e aprendizado da educação profissional de forma que as atividades mentais propostas na pesquisa como princípio pedagógico sejam ampliadas nesses sujeitos por meio da produção de textos específicos para esse fim.

\section{REFERÊNCIAS}

ASSOCIAÇÃO BRASILEIRA DE NORMAS TÉCNICAS. NBR 10520: Informação e documentação: citação em documentos. Rio de Janeiro, 2002.

BAKHTIN, M. Problemas da poética de Dostoiévski. Tradução Paulo Bezerra. Rio de Janeiro: Forense Universitária, 1981 [1929]. [1930].

Estética da criação verbal. 3. ed. São Paulo: Martins Fontes, 2003

BAZERMAN C. Writing to learn. In: BAZERMANN, Charles et al. Reference Guide to Writing cross the Curriculum. Parlor Press and the WAC clearinghouse. 2005. Disponível em: < wac.colostate.edu/books/bazerman_wac/chapter5.pdf>. Acesso em: 5 maio 2010.

BRASIL. Secretaria de Educação Fundamental. Parâmetros Curriculares Nacionais. Terceiro e quarto ciclos do ensino fundamental: apresentação dos temas transversais - Brasília: MEC/SEF, 1998. Disponível em: < portal.mec.gov.br/seb/arquivos/pdf/ttransversais.pd>. Acesso em: 30 agos. 2013.

BRASIL. Secretaria da Educação. Parâmetros Curriculares nacionais. Ensino Médio: Linguagens, códigos e suas tecnologias. 2000. Disponível em: $<$ portal.mec.gov.br/seb/arquivos/pdf/linguagens02.pd>. Acesso em: 30 mar. 2014.

BRASIL. Ministério da Educação. Conselho Nacional de Educação. Conselho Pleno. Parecer CNE/CP 009, de 8 de maio de 2001. Diretrizes Curriculares Nacionais para a Formação de Professores da Educação Básica, em nível superior, curso de licenciatura, de graduação plena. Diário Oficial da República Federativa do Brasil. Poder Executivo, Brasília, DF. 18 jan. 2002, Seção 1, p. 31. Disponível em:

<http://portal.mec.gov.br/cne/arquivos/pdf/009.pdf>. Acesso em: 10 jun. 2014. BRASIL. Ministério da Educação. Secretaria da educação. Orientações Educacionais Complementares aos Parâmetros Curriculares Nacionais. 
Linguagens, Códigos e suas Tecnologias. 2002. Disponível em: $<$ portal.mec.gov.br/seb/arquivos/pdf/linguagens02.pdf>. Acesso em: 30 mar. 2014.

BRASIL. Ministério da Educação. Conselho Nacional da Educação. Câmara de Educação Básica. Resolução № 6, de 20 de setembro de 2012. Diretrizes Curriculares Nacionais para a Educação Profissional Técnica de Nível Médio. Diário Oficial da República Federativa do Brasil, Poder Executivo, Brasília, DF, 21 set. 2012, Seção 1, p. 22. 2012a.

BRASIL. Ministério da Educação. Secretaria de Educação Profissional e Tecnologia. Catálogo Nacional dos Cursos Técnicos. 2012b. Disponível em: <portal.mec.gov.br/index.php?option=com_docman\&task>. Acesso em: 30 mar. 2013.

BRASIL. Ministério da Educação. Secretaria de Educação Básica. Secretaria de Educação Continuada, Alfabetização, Diversidade e Inclusão. Conselho Nacional da Educação. Diretrizes Curriculares Nacionais Gerais da Educação Básica. Brasília: MEC, SEB, DICEI, 2013. 542p. Disponível em:< file://C:/Users/User/Downloads/diretrizes_curiculares_nacionais_2013\%20(3). pdf>. Acesso em: 10 mar. 2014.

CHARTIER, Roger. Hábito de ler está além dos livros, diz um dos maiores especialistas em leitura do mundo. Agência Brasil. 24 jun. 2012. Entrevista concedida a Amanda Cieglinsk . Disponível em:

<agenciabrasil.ebc.com.br/.../habito-de-ler-esta-alem-dos-livros-diz-u...>. Acesso em: 10 set. 2012.

DUCROT, O. O dizer e o dito. Revisão técnica da tradução Eduardo Guimarães. Campinas, SP: Pontes, 1987 [1984].

GOMBERT, J. E. Metalinguístic development. Chicago: University of Chicago Pres, 1992.

- Metacognition, Metalanguage and Metapragmatics. International Journal of psychology. V. ${ }^{28}$ (5), 1993, p. 571-580. Acessível em: <http://valtweb2a.valt.helsinki.fi/blogs/harmo/meta>. Acesso em: 2 fev.2010.

Metalinguagem e aquisição da escrita. In: MALUF, M. R. (Org.). Aquisição da escrita: contribuições da pesquisa para a prática da alfabetização. São Paulo: Casa do Psicólogo, 2003.

$\mathrm{KOCH}, \mathrm{I}$. G. V. Introdução à linguística Textual: trajetória e grandes temas. São Paulo: Martins Fontes, 2004.

. 0 texto e a construção dos sentidos. 9 ed. 1‥ Reimpressão - São Paulo: Contexto, 2008 [1997].

MAINGUENEAU, D. Polifonia. In: Elementos de linguística para o texto literário. São Paulo: Martins Fontes, 2001 [1986] p. 85-102.

Análise de textos de comunicação. Tradução de Cecília P. de Souza-e-Silva, Décio Rocha. - 5. ed. - São Paulo: Cortez:2008.

MARCUSCHI, L. A. Produção textual, análise de gêneros e compreensão. São Paulo: Parábola. 2008. 
ROJO, R. (Org.). Escola conectada: os multiletramentos e as TICs. São Paulo: Parábola, 2013.

SCHNEUWLY, B.; DOLZ, J. Os gêneros escolares - das práticas de linguagem aos objetos de ensino. In: Gêneros orais e escritos na escola. Tradução e organização Roxane Rojo e Glais Sales Cordeiro. 2. ed. Campinas, SP: Mercado de Letras, 2010.

SEVERINO, A. J. Metodologia do trabalho científico. 23. ed. rev. e atual. São Paulo: Cortês, 2007.

THIOLLENT, Michael. Metodologia da pesquisa-ação. 14. ed. - São Paulo: Cortez, 2005.

VALER, S. Competência produtiva escrita: processos argumentativos dos alunos da quinta série do Ensino Fundamental. 2012 - Tese (Doutorado) Universidade Federal de Santa Catarina, Centro de Comunicação e Expressão, Programa de Pós-Graduação em Linguística, Florianópolis, 2012. Disponível em:<www.repositorio.ufsc.br/xmlui/handle/123456789/100892>. Acesso em: 13 jul. 2013.

VIGOTSKI, L. S. A formação social da mente. 7. ed. São Paulo: Martins Fontes, 2008 [1930]. 